\title{
Gambaran Kepadatan Tungau Debu Rumah Sebagai Pencetus Rinitis Alergi pada Anak Panti Asuhan Pekanbaru
}

\author{
Yolazenia $^{1^{*}}$, Harianto ${ }^{2}$, Iqbal Teguh Riady ${ }^{3}$
}

\begin{abstract}
Allergic rhinitis should be considered as a serious condition because it can affect the quality of life of patients. In many cases, the most common allergen is house dust mites (HDM). The purpose of this study was to describe the density of house dust mites as triggers of allergic rhinitis in Pekanbaru orphanage children. This is a descriptive study with a cross sectional approach. Data obtained from interviews using the modified International Study of Asthma and Allergies of Childhood (ISAAC) questionnaire to know the allergic rhinitis status and examination of house dust samples to identify HDM in the parasitology laboratory. Sampling was carried out in 4 orphanages Pekanbaru. Allergic rhinitis symptoms were experienced by $81.2 \%$ of children in the orphanages and HDM was found with the mean density $9.11 /$ $\mathrm{g}$ of dust. HDM was found in all four orphanages and was found to have a high incidence of allergic rhinitis.
\end{abstract}

Keywords: allergic rhinitis, house dust mite, orphanage

Rinitis alergi dapat didefinisikan sebagai kumpulan gejala pada hidung yang disebabkan inflamasi yang dimediasi oleh IgE akibat paparan alergen. Gejala yang ditimbulkan berupa bersinbersin, rinore, rasa gatal dan sumbatan pada hidung. Rinitis alergi harus dipikirkan sebagai keadaan yang cukup serius karena dapat mempengaruhi kualitas hidup penderita akibat beratnya gejala yang dialami. Penderita akan mengalami keterbatasan dalam aktifitas sehari-hari, sering meninggalkan sekolah atau pekerjaannya dan menghabiskan biaya yang besar jika menjadi kronis. ${ }^{1}$

Rinitis alergi merupakan masalah kesehatan pada $10 \%$ penduduk di dunia atau sekitar 500 juta penduduk di dunia. Prevalensi rinitis alergi pada masing-masing negara berbeda-beda misalnya Thailand 20\%, Singapura 15\%, Malaysia 17\%, sedangkan Indonesia 15\%. Ditinjau dari segi usia rinitis alergi timbul sejak bayi, terlihat meningkat pada umur 5 - 10 tahun, dengan puncaknya umur 20 tahun, kemudian menurun pada usia 30 tahun. ${ }^{2}$

\footnotetext{
* Corresponding author : yolazenia@lecturer.unri.ac.id

KJFD Parasitologi Fakultas Kedokteran Universitas Riau Pekanbaru

2 KJFD THT-KL Fakultas Kedokteran Universitas Riau Pekanbaru

3 Mahasiswa Fakultas Kedokteran Universitas Riau Pekanbaru
}

Prevalensi rinitis alergi di Indonesia cenderung meningkat setiap tahunnya. Menurut penelitian Sarumpaet $\mathrm{RD}^{3}$ pada bulan Agustus dan September 2013 didapatkan 96 kasus rinitis alergi yang datang ke Poliklinik Telinga Hidung Tenggorokan Kepala dan Leher (THT-KL) Rumah Sakit Umum Daerah (RSUD) Arifin Achmad Provinsi Riau, dengan rentang usia terbanyak 15-25 tahun. ${ }^{3}$

Pada banyak kasus rinitis alergi, alergen yang paling banyak ditemukan adalah tungau debu rumah (TDR). Jenis TDR yang paling sering ditemukan di Indonesia terdiri dari 2 jenis yaitu Dermatophagoides pteronyssinus (D. pteronyssinus) dan Dermatophagoides farina (D.farinae). ${ }^{4}$ Penelitian Rafi ${ }^{5}$ mendapatkan alergen TDR yang paling banyak ditemukan pada mahasiswa yang menderita rinitis alergi adalah D.farinae $(63,51 \%)$ diikuti dengan D.pteronyssinus $(60,81 \%)$ dan Blomia tropicalis $(58,10 \%)$.

Penderita alergi yang terpapar alergen TDR dapat menimbulkan kekambuhan penyakit rinitis alergi. Jumlah TDR terbanyak ditemukan pada perabotan di kamar tidur seperti kasur, seprai, selimut dan karpet. Keberadaan TDR pada perabot kamar tidur erat kaitannya dengan makanan tungau. Skuama merupakan makanan pokok TDR dan pada 
tempat tidur banyak tersedia skuama atau serpihan kulit manusia. ${ }^{4,6}$

Banyak faktor yang menyebabkan tingginya keberadaan TDR di kamar tidur. Salah satu faktor yang menyebabkan tingginya morfologi hidup TDR ialah masyarakat jarang membersihkan kamar tidur yang banyak mengandung serat-serat sehingga lebih mudah menampung debu seperti kasur, selimut, seprai, boneka, sofa dan sarung bantal. Faktor lain seperti suhu dan kelembaban juga menjadi faktor utama yang mempengaruhi pertumbuhan dan perkembangan tungau. Upaya menghindari pajanan dan pemberantasan TDR dapat dilakukan dengan cara menjaga kebersihan kamar tidur secara teratur seperti menyapu dan mengepel lantai setiap hari, membersihkan perabotan kamar menggunakan lap basah, mengganti seprai, selimut dan sarung bantal serta menjemur tempat tidur sekali seminggu. Suhu yang optimal bagi perkembangan TDR adalah 25$30^{\circ} \mathrm{C}$ dengan kelembaban $70-80 \%$, untuk mengurangi kelembaban pada suhu kamar dilakukan dengan cara air conditioner (AC) diservis setiap 6 bulan dan mengupayakan sinar matahari dapat masuk ke dalam kamar. ${ }^{6,7}$

Tujuan penelitian ini adalah untuk mengetahui gambaran kepadatan tungau debu rumah sebagai pencetus terjadinya rinitis alergi pada anak panti asuhan di Kota Pekanbaru.

\section{METODE}

Penelitian ini merupakan penelitian deskriptif dengan pendekatan cross-sectional. Penelitian mendapat ethical clearance dari panitia tetap kaji etik Fakultas Kedokteran Universitas Riau. Pengambilan sampel dilakukan di 4 Panti Asuhan kota Pekanbaru. Pemillihan panti asuhan di kota Pekanbaru dilakukan secara purposive sampling. Pemeriksaan sampel debu rumah dilakukan di Laboratorium Parasitologi FK UNRI. Penelitian dilaksanakan mulai dari bulan Juli hingga November 2018.

\section{Cara pengambilan sampel debu}

Cawan petri disiapkan, diberi label nomor dan nama ruangan, untuk tempat debu dari tiap - tiap ruangan. Debu dari setiap ruangan diambil menggunakan vaccum cleaner lalu diletakkan ke dalam cawan petri. Selanjutnya dilakukan penimbangan menggunakan timbangan analitik. Debu dibagi setiap 1 gram untuk selanjutnya siap untuk diperiksa.

\section{Cara pemeriksaan spesimen}

Metode untuk mendeteksi kehadiran tungau adalah dengan cara meletakkan sejumlah debu pada permukaan air dan memeriksanya dengan perbesaran 20 kali. Tungau mati dan yang hidup akan terlihat mengambang pada permukaan air tersebut.

\section{Identifikasi tungau debu rumah}

Untuk mengidentifikasi tungau digunakan jarum tungau untuk mengangkat tungau, lalu tungau diletakkan di atas kaca benda untuk dibuat preparat, kemudian diperiksa dengan mikroskop.

\section{Identifikasi Rinitis alergi}

Untuk mengidentifikasi rinitis alergi pada sampel menggunakan kuesioner modifikasi International Study of Asthma and Allergies of Childhood (ISAAC).

\section{HASIL}

\section{Karakteristik Responden}

Penelitian dilakukan di 4 panti asuhan di Pekanbaru dengan rincian jumlah responden dapat dilihat pada tabel 1 .

Tabel 1. Jumlah Responden pada masing-masing Panti Asuhan

\begin{tabular}{ccc}
\hline Panti Asuhan & $\mathrm{n}$ & $\%$ \\
\hline A & 42 & 30,4 \\
B & 28 & 20,3 \\
C & 46 & 33,3 \\
D & 22 & 15,9 \\
\hline Total & 138 & 100 \\
\hline
\end{tabular}

Jumlah total responden dari keempat panti asuhan adalah sebanyak 138 orang. Responden yang berjenis kelamin laki-laki sama banyak dengan 
perempuan masing-masing 69 orang, dengan umur rata-rata $13,85 \pm 2,24$. Berdasarkan pendidikan, sebagian besar responden berpendidikan SMP yaitu 64 orang $(46,4 \%)$ diikuti SMA 42 orang $(30,4 \%)$ dan SD 32 orang $(23,2 \%)$.

\section{Distribusi Frekuensi Status Rinitis Alergi berdasarkan kuesioner ISAAC pada Anak Panti Asuhan Pekanbaru}

Tabel 2. Distribusi Frekuensi Status Rinitis Alergi berdasarkan kuesioner ISAAC pada Anak Panti Asuhan Pekanbaru

\begin{tabular}{ccc}
\hline Panti Asuhan & $\mathrm{n}$ & $\mathbf{\%}$ \\
\hline A & $33 / 42$ & 78,6 \\
B & $24 / 28$ & 85,7 \\
C & $40 / 46$ & 87,0 \\
D & $15 / 22$ & 68,2 \\
\hline Total & $112 / 138$ & 81,2 \\
\hline
\end{tabular}

Pada tabel 2 terlihat, secara keseluruhan didapatkan persentase status rinitis alergi berdasarkan kuesioner ISAAC pada anak panti asuhan adalah sebesar $81,2 \%$.

\section{Distribusi Frekuensi Kepadatan Tungau Debu Rumah pada Panti Asuhan Pekanbaru}

Tabel 3. Kepadatan Tungau Debu Rumah (TDR) pada Panti Asuhan Pekanbaru

\begin{tabular}{cc}
\hline Panti Asuhan & $\begin{array}{c}\text { Rata-rata TDR } \\
\text { /gram debu }\end{array}$ \\
\hline A & 8,76 \\
B & 8,17 \\
C & 9,49 \\
D & 10,03 \\
\hline Total & 9,11 \\
\hline
\end{tabular}

Pada tabel 3 terlihat rata-rata kepadatan TDR pada panti asuhan di Pekanbaru sebesar 9,11/g debu.

\section{PEMBAHASAN}

\section{Distribusi Frekuensi Status Rinitis Alergi berdasarkan kuesioner ISAAC pada Anak Panti Asuhan Pekanbaru}

Status rinitis alergi yang ditemukan pada anak panti asuhan Pekanbaru adalah 81,2\% lebih tinggi dibandingkan yang didapatkan oleh Nova $\mathrm{dkk}^{8}$ yang melakukan penelitian di dua panti asuhan Kecamatan Koto Tangah Padang dengan menggunakan metoda yang sama untuk mengidentifikasi alergi (kuesioner ISAAC) mendapatkan $41,5 \%$ anak mengalami rinitis alergi. Prevalensi rinitis alergi secara global bervariasi dari 2 sampai $25 \%$ pada anak dan $1 \%$ sampai lebih dari $40 \%$ pada dewasa. ${ }^{9}$ Memang terdapat kecenderungan peningkatan prevalensi pada negara yang sebelumnya prevalensinya rendah. Prevalensi rinitis alergi di Asia terakhir mengalami peningkatan yaitu sekitar $45 \%$ dan paling banyak di negara miskin dan berkembang. ${ }^{10}$ Hal ini juga mungkin terjadi di Indonesia seperti yang didapatkan pada penelitian. Salah satu penyebabnya karena kurangnya kebiasaan menjaga kebersihan terutama kamar tidur sehingga banyak ditemukan tungau debu rumah yang merupakan alergen penyebab rinitis alergi yang paling banyak ditemukan. ${ }^{11}$

Bila dianalisis lebih lanjut untuk melihat klasifikasi responden yang mengalami rinitis alergi berdasarkan WHO-ARIA didapatkan sebagian besar responden tergolong rinitis alergi intermiten yaitu $82 \%$ yang mengalami gejala kurang dari 1 bulan dan $73,9 \%$ yang mengalami gejala kurang dari 4 hari. Berdasarkan pengaruhnya terhadap aktivitas, sebagian besar responden menyatakan tidak berpengaruh atau sedikit pengaruhnya terhadap aktivitas (73\%), hanya $27 \%$ yang menyatakan berpengaruh sedang sampai berat terhadap aktivitas sehari-hari. Dengan demikian, dapat disimpulkan sebagian besar responden yang mengalami gejala rinitis alergi tergolong dalam rinitis alergi intermiten ringan.

Kuesioner untuk mendeteksi kejadian alergi yang dikeluarkan oleh International Study of Asthma and Allergies of Childhood (ISAAC) merupakan kuesioner yang sudah terstandarisasi. ${ }^{12}$ Bagaimanapun kekurangan dari penggunaan kuesioner untuk penjaringan suatu penyakit dapat menjadi over atau underdiagnostic disebabkan kemungkinan terjadinya mispersepsi dari responden 
terhadap isi kuesioner. Oleh karena itu sebaiknya untuk mengklarifikasi kejadian rinitis alergi perlu ditunjang juga dengan uji cukit kulit (skin prick test) menggunakan alergen yang sering ditemukan tetapi tidak dilakukan pada penelitian ini.

\section{Distribusi Frekuensi Kepadatan Tungau Debu Rumah pada Panti Asuhan Pekanbaru}

Rata-rata kepadatan TDR pada panti asuhan di Pekanbaru sebesar 9,11/g debu. Kepadatan TDR ini hampir sama dengan yang didapatkan Ponggalunggu $\mathrm{dkk}^{11}$ di kelurahan Malalayang I Manado yang mendapatkan 10,26/g debu pada tempat tidur, 6,85/g debu pada lantai kamar tidur dan 25,51/g debu pada sofa. Penelitian Widiastawan $\mathrm{dkk}^{13}$ di Kelurahan Malalayang II, Manado mendapatkan kepadatan TDR di tempat tidur 36,92 tungau/g debu, di sofa 15,94 tungau/g debu, dan di lantai kamar tidur 11,41 tungau/g debu dengan rerata 21,42 tungau/g debu. Pada penelitian ini sampel debu diambil dari seluruh kamar tidur dan dipisahkan per panti karena sulit untuk memisahkan per individu disebabkan anak-anak yang tinggal di panti asuhan tidur secara beramai-ramai dalam 1 kamar dan alas tidur (kasur) kadang ditumpuk bila tidak terpakai sehingga tidak sama setiap harinya untuk satu individu.

TDR khususnya D.pteronyssinus dan D.farinae merupakan $50-80 \%$ penyebab asma dan rhinitis alergi di seluruh dunia menurut $\mathrm{WHO}^{4}$ Bagian tubuh TDR yang biasa menjadi alergen adalah kutikula, organ seksual dan saluran pencernaan. Antigen yang berasal dari tubuh TDR masuk ke tubuh manusia melalui penetrasi kulit, sedangkan yang berasal dari feses masuk melalui inhalasi. ${ }^{10}$ Disamping kurangnya faktor menjaga kebersihan, suhu dan kelembaban udara juga berpengaruh terhadap berkembangnya TDR. Untuk dapat bertahan hidup, TDR membutuhkan suhu 25 $-30{ }^{\circ} \mathrm{C}$ dan kelembaban antara $70-80 \% .{ }^{11}$

Kepadatan TDR merupakan jumlah TDR yang terdapat dalam satu gram debu. Pajanan TDR sebanyak 100-500 tungau/gram atau $10 \mathrm{mg}$ Der p1 per gram debu merupakan faktor risiko terjadinya reaksi alergi. ${ }^{4}$ Pada penelitian ini kepadatan TDR yang didapatkan lebih rendah, salah satu kemungkinan penyebab hal ini adalah faktor kekuatan vaccum cleaner yang digunakan sehingga tidak optimal dalam mengambil sampel debu rumah. Rinitis alergi yang ditemukan pada anak-anak panti asuhan Pekanbaru sebagian besar tergolong rinitis alergi intermiten ringan, hal ini mungkin disebabkan karena kepadatan TDR yang ditemukan juga tidak terlalu tinggi. Nova $\mathrm{dkk}^{8}$ mendapatkan kepadatan TDR pada penderita rintis alergi yaitu 6,29 tungau dan non rinitis alergi sebanyak 6,33 tungau dan tidak terdapat perbedaan bermakna antara paparan TDR dengan status rinitis alergi pada anak. Mantu $\mathrm{dkk}^{10}$ mendapatkan tidak terdapat hubungan yang bermakna antara kepadatan TDR dengan derajat rinitis alergi. Tetapi hal ini tidak menyingkirkan kemungkinan TDR sebagai alergen penyebab rinitis alergi pada anak-anak penghuni panti. Bagaimanapun untuk diagnosis pasti diperlukan pemeriksaan skin prick test atau pemeriksaan IgE spesifik pada masing-masing individu untuk memastikan alergen penyebab.

\section{SIMPULAN}

Pada keempat panti asuhan didapatkan TDR, dengan kepadatan TDR rata-rata 9,11/gram debu dan sebagian besar anak-anak penghuni panti asuhan pernah mengalami gejala rinitis alergi $(81,2 \%)$.

\section{DAFTAR PUSTAKA}

1. Bousquet J, Khaltaev A, Cruz A, Denburg J, Fokkens W.J, Tokias A et all. Allergic rhinitis and its impact on astma. Eropean journal of allergy and clinical immunology. 2008; 63: 20-28

2. Putu WS. Pemeriksaan eosnofil usapan mukosa hidung sebagai kriteria diagnosis rinitis alergi di RSUD Dr. Moewardi Surakarta. [Skripsi]. Surakarta:Universitas Sebelas Maret, 2008.

3. Sarumpaet RD, Juffrie M, Suprihati, Astuti I. Pengaruh asap rokok terhadap kualitas hidup total penderita rhinitis alergi persisten. Jurnal Skolastik Keperawatan. 2016;1(2):1-12.

4. Natalia D. Peranan alergen tungau debu rumah (Der p 1 dan Der p 2) dalam Reaksi Alergi. CDK227. 2015;42(4):251-5.

5. Rafi M. Gambaran rinitis alergi pada mahasiswa Fakultas Kedokteran Universitas Riau angkatan 
2013 dan 2014. [Skripsi]. Pekanbaru : Universitas Riau. 2015

6. Kaisa S, Lars W. Bedrooms without house dust mites. Lund University. 2005; 1-70.

7. Aulung A. Aspek biologi dan ekologi TDR. Disampaikan dalam Simposium penatalaksanaan penderita asma dengan perbaikan kondisi lingkungan. Jakarta, 21 Juli 1992.

8. Nova DF, Rusjdi SF, Fitri F. Perbedaan paparan tungau debu rumah dengan status rhinitis alergi berdasarkan kriteria ISAAC pada anak di dua panti asuhan kecamatan koto tangah. JKA. 2018;7(2):253-7.

9. Brozek JL, Bousquet J, Agache I, Agarwal A, Bachert C, Bosnic-Anticevich S, et al. Allergic Rhinitis and its Impact on Asthma (ARIA) guidelines-2016 revision. J Allergy Clin Immunol. 2017;140:950-8.
10. Mantu BG, Wahongan GJ, Bernadus JB. Hubungan kepadatan tungau debu rumah dengan derajat rhinitis alergi. Jurnal e-Biomedik. 2016;4(1):1-8

11. Ponggalunggu WF, Pijoh VD, Wahongan GJP. Jenis dan kepadatan tungau debu rumah pada beberapa habitat di rumah penderita penyakit alergi. Jurnal e-Biomedik (eBm). 2015; 3(1):25460

12. International Study of Asthma and Allergies of Childhood (ISAAC) Steering Committee. Phase Three Manual International Study of Asthma and Allergies of Childhood. ISAAC phase three; 2000. Diakses dari: http://isaac.auckland.ac.nz/

13. Widiastawan KAW, Wahongan GJB, Bernadus JBB. Jenis dan kepadatan tungau debu rumah di kelurahan Malalayang dua kecamatan Malalayang kota Manado. Jurnal e-Biomedik (eBm). 2015; 3(3):733-7. 